\title{
Algunos libros últimos \\ sobre el ministerio de Pedro (II)
}

\author{
José Ignacio González Faus, \\ Facultad de Cataluña, \\ Centro de Reflexión Teológica, San Salvador.
}

Valentín Fábrega Escatllar, La herejla vaticana, Ed. siglo XXI. Madrid 1996. 138 págs.

Klaus Schatz. El primado del papa. Su historia desde los orfgenes hasta nuestros dias, Sal Terrae, Santander 1996, 252 págs.

H. Fischer, St. Horn, W. Kasper, H. Pottemeyer, Wozu noch einen Papst? Vier Plädoyers für das Petrusamt, Ed. Communio, Köln 1993, 87 págs.

M. Kehl, La Iglesia, Sígueme, Salamanca 1996 (ver Actualidad Bibliográfica, 1196, págs. 155-163).

J. M. Tillard. L'Eglise locale, Du Cerf. París 1995 (ver Actualidad Bibliográfica, 1996, págs. 167-171).

AA. VV., Pedro en la Iglesia primitiva, (editor R. Aguirte), Verbo Divino, Estella 1991, 258 págs.

\section{La evolución posterior del papado hasta el fin del primer milenio}

Los siglos $\mathrm{V}$ a $\mathrm{X}$ arrojan una situación y una evolución muy distinıa para oriente y occidente. El oriente pervive y es imperio. Occidente ha quedado hundido y ha de reconstruirse. En su resurgimiento será decisiva la ayuda de Roma como constitutivo de identidad. A la vez, oriente nunca aceptará cierto estilo "imperial" al que Roma no acaba de renunciar, y que será un factor comprensible de conflictividad. Desde aquí se percibe ya que la evolución va a ser muy distinta en cada uno de estos dos bloques eclesiales.

\subsection{Occidente}

En occidente hay que comenzar hablando de una cierta decadencia o latencia del papado recién constituido. Después de san León, las demandas y cartas a Roma disminuyen sensiblemente. Entre las causas de ese descenso no sólo está 
una cierta pérdida de prestigio de Roma (caso del papa Vigilio del que hablaremos más adelante en este capítulo), sino la misma atonía y falta de vitalidad de aquella hora histórica. De las diversas "unidades eclesiales" de occidente (norteafricana, visigoda, franca, Milán-Aquileya y la naciente Iglesia irlandesa), la más vigorosa es la segunda, y la institución más importante son los concilios de Toledo: convocados por el rey, "llegan incluso a promulgar definiciones dogmáticas sin consultar al papa o solicitar su ratificación" (Schatz, 99). Simplemente se comunicaban las actas ad informationem. Y los contactos entre la España visigoda y Roma delatan más bien unas ralaciones frías, debido a cierta "mezquinidad y doctrinarismo" romanos (Schatz, 100) y a la superioridad teológica de los visigodos. En cualquier caso merece citarse la conclusión de Schatz:

Las iglesias incorporaron parcialmente decretos papales en sus colecciones canónicas, mezclándolos con otras tradiciones jurídicas. Tenían su propia liturgia, con formas que les eran propias, aunque todas utilizaran la lengua latina. Sólo se puede hablar de una dirección real de la Iglesia por el papa en las provincias eclesiales romanas, es decir, en la antigua Italia suburbicaria con las islas (Schatz, 100, cursivas nuestras).

En cambio, hacia el siglo VII, los misioneros anglosajones en el norte de Europa (fruto de la célebre iniciativa del papa Gregorio I hacia Inglaterra) transmitirán su vinculación con Roma y para aquellas iglesias nacientes se convierte en usual la consulta a Roma (sobre todo con san Bonifacio), no tanto para "solicitar nuevas decisiones", sino para "preguntar cuál es la tradición más antigua" "de la que ellos carecen y de la que Roma es testigo auténtico.

A fines del siglo VIII resurge el papel de Roma por una serie de causas.

a) Causas políticas, como el afán de unidad imperial de Carlomagno que le lleva hasta la adopción de usos rituales y litúrgicos romanos, en clara contrariedad con lo que había sido el afán misionero e inculturador del papa Gregorio I, ansioso por respetar todas las diferencias y pluralidades. Pero Carlornagno sólo considera a Roma y a la tradición romana como criterio por el cual se miden todas las cosas. Sin embargo, "quien mide y quien decide es el rey" (Schatz, 105).

b) Causas de unidad eclesial. Roma había recobrado importancia cuando, en el siglo anterior, hubo un nuevo conflicto sobre la fecha de la pascua, esta vez con las iglesias de Irlanda. El conflicto acabó resolviéndose con una argumentación demasiado simple y hasta supersticiosa: san Pedro tiene en el cielo más poder que [san] Columbano. Pero volvió a descubrir el valor de la unidad y la necesidad de un ministerio para ellal.

1. En aquellas sociedades cerradas resultaba intolerable que el mismo día en que unos estaban de fiesta, otros siguieran ayunando: división que llegó a darse incluso entre el rey y la reina. 
c) Causas misioneras que recogen ahora los frutos de la misión enviada por Gregorio Magno a los anglosajones dos siglos antes. Roma inició con sus primeros obispos (York y Canterbury) una práctica que ahora se generalizará: la entrega a los metropolitas de un lazo de lana blanca (pallium) que había estado sobre la tumba de Pedro, y que simbolizaba la comunión con el centro. Al generalizarse este uso a todos los metropolistas, en el siglo VIII, el pallium pasa de "simple signo de comunión" a "símbolo de trasmisión de poder" (Schatz 103). $Y$ acabará teniendo importancia decisiva en la guerra de las investiduras.

En el siglo IX surgen las llamadas Pseudodecretales, una falsificación de documentos que, para Döllinger, constiluja el primer paso no auténtico de toda esta evolución, que la iba convirtiendo de desarrollo en tumor. Se trata de una colección de supuestos documentos de papas anteriores (junto a otros auténti$\cos$ ) que dan una imagen decisiva y supercentralista de la autoridad y actividad de Roma. Pero lo curioso es que este documento no nace en Roma sino en Reims. Y su objetivo no era tanto reforzar la autoridad de Roma cuanto quebrar la de los metropolitas, que Carlomagno había reforzado mucho para poder controlarlos mejor (rompiendo así el ejercicio de la "colegialidad" episcopal). Las Pseudodecretales obedecen a un doble principio que marcará toda la posterior historia del papado: a) buscar un punto de apoyo para tener independencia frente a los monarcas. b) Una autoridad fuerte, es mejor si está lejos que si está demasiado cerca. Pues bien, es en ellas donde se vuelven casi definitivo: 1) que Roma es instancia no sólo de revisión, sino de apelación (contra lo que sostenía el metropolita de Reims Hincmaro); y 2) que los concilios y sínodos adquieren fuerza de ley al ser ratificados por Roma.

Las Pseudodecretales suponen, por tanto, un paso decisivo en la aparición de "estructuras supradiocesanas ligadas a la autoridad papal" (Schatz, 110). Su importancia no puede minusvalorarse, pese a que durante un tiempo no fueron aceptadas por muchos obispos (por ejemplo, en el sinodo de Versy, en 991). Son una contribución "decisiva al desvanecimiento de la idea de una colegialidad episcopal autónoma" (Schatz 110). Y dejarán además en germen la idea de que toda autoridad episcopal es una mera institución de la autoridad papal2. La entrega del pallium cambiará aquí de significado; y la antigua concepción más horizontal queda herida de muerte ante una visión más vertical y más centralizada. No obstante Schatz subraya, en contra de Döllinger, que el factor decisivo de esta evolución no ha sido sólo "la voluntad de poder de Roma", sino el "no funcionamiento de las estructuras eclesiales antiguas" (Schatz, 111). Estamos en la constante de la autonomía de la historia que, para bien o para mal, no siempre funciona de acuerdo al ideal del evangelio.

2. "Los papas instiluyen a los arzobispos que deben asumir su representación en las iglesias" (MGH, Script. VII, 404). Palabras de una nueva falsificación, aparecida en Salzburgo hacia el 970. 
En cualquier caso, y como fruto de este nuevo paso, desde el siglo $X$ compete a Roma fundar nuevas diócesis, cosa que antes habían hecho los obispos vecinos, y luego pasó a ser competencia... de los reyes.

El último paso de este proceso es el valor que cobra desde el siglo XI una frase ya antigua (y también fruto de otra falsificación), pero que ahora ocupará el horizonte: primo sedes a nemine iudicasur (nadie puede juzgar a la sede romana). La fórmula procede de las Falsificaciones de Sínaco (hacia el año 500). Este papa, partidario del rey ostrogodo (y arriano) Teodorico, se vio enfrentado a su clero romano, partidario de Bizancio, que quiso deponerlo. Para evitar esa deposición aparecieron estas falsificaciones que se remitfan a supuestos episodios de siglos anteriores. La máxima no hizo fortuna una vez superado el conflicto. Pero a fines del milenio irá pasando a ser "constitutivo de la tradición jurídica romana" (Schatz, 113).

Cabe discutir si esta máxima entra o no en la lógica de "Roma centro de comunión". Lo claro es que no podía imponerse, porque entonces no eran raros los cismas en el papado o las deposiciones de papas (por conductas simoníacas etc.). Ahora bien, cuando había dos papas, ¿cuál es la primera sede? Sólo cuando en 1179 se regule jurídicamente la elección papal, evitando los cismas, y la autoridad del emperador evite las deposiciones arbitrarias de papas, podrá imponerse la máxima.

Pero con sus excepciones. Porque aunque vaya aceptándose la máxima, queda viva la evidencia histórica de que el papa puede caer en herejía. La respuesta del momento a esta hipótesis será que, en ese caso, eo ipso deja de ser papa (apelando a Juan 3, 18: "quien no cree ya está juzgado"). Con lo que la conducta de la persona no implica un juicio sobre la sede; y nuestra máxima hablaba de la sede, no del primus episcopus o algo asl. Esta distinción, quizá más térica que práctica, seguirá siendo válida durante mucho tiempo.

Como conclusión, en occidente tenemos, pues, una evolución que va claramente en la línea del crecimiento del papado. En oriente, la historia marchará en un sentido, si no inverso, al menos profundamente diverso. Vamos a verlo ahora.

\subsection{Oriente}

Según Schatz, las relaciones entre occidente y oriente en esta segunda mitad del primer milenio están marcadas por cinco grandes conflictos que rienen una doble causa común. Comencemos por las causas.

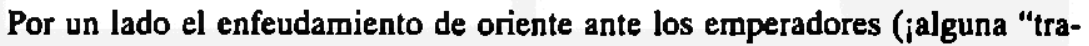
dición" debió crear aquello de Eusebio de que Constantino era "el treceavo apóstol"!). "En todos los grandes conflictos eclesiales, el viraje se produjo siernpre con ocasión de un cambio de poder en Constantinopla" (Schatz, 80). Y es 
cierto que Roma procura no ceder ante ese cesaropapismo, pese a que la misma elección del obispo de Roma por el clero de la diócesis, necesita ser ratificada por el emperador.

Pero también Roma comienza a intervenir en oriente con poco tacto y sin suficiente información. La decadencia de occidente tampoco le da mucha autoridad, y entre los bizatinos comienza a crecer "la alergia al occidente bárbaro y a sus tentativas de ingerencia" (Schatz, 81), aunque otras veces necesiten a ese occidente, no sólo frente al emperador, sino frente a los monofisitas, aliados siempre con cualquier poder enemigo de Constantinopla. Los concilios ecuménicos siguen celebrándose en oriente y por convocaloria imperial, con algún documento romano que intenta marcar el camino, pero no pos su autoridad personal, sino por la autoridad de la tradición que Roma posee. No obstante merece positiva reseña el III de Constantinopla (el 681), con participación de representantes de los cinco patriarcados, y una espléndida acogida a la carta del papa Agatón sobre la que el concilio afirma: "la antigua ciudad de Roma ha presentado una confesión de fe cristiana escrita por Dios $y$, desde occidente, ha hecho amanecer el día para el dogma. Parecía papel y tinta pero, a través de Agatón, es Pedro quien ha hablado" (citado en Schatz, 84).

Si éstas son las horas buenas, no pueden hacer olvidar el rosario de conflictos que va creando también un estímulo de precedentes. Hélos aquí.

El cisma de Acacio, patriarca de Constantinopla, en el paso del siglo $\mathrm{V}$ al V. Su motivo fue un documento que intentaba reintegrar a los monofisitas sin mencionar la fómula calcedónica, pero sin negar su contenido (semejante, por tanto, en esto al que suscribieron, en 1984, el papa Juan Pablo Il y el patriarca copto). Roma excomulgó a Acacio, éste rompió con Roma y el cisma duro 35 años.

El papa Vigilio condenado y excomulgado por el Concilio II de Constantinopla. Aquí estuvo en juego otra vez el afán por reconquistar a los monofisitas, condenando como nestorianos a los tres grandes patriarcas de oriente. Pienso que el papa se encontró sencillamente entre dos fuegos y no pudo hacer casi nada. Y no considero éste como uno de los mayores errores del papado, pese a lo mucho que se ha jugado con él. Pero es innegable que Vigilio condenó primero a los tres orientales, con lo que todo occidente le acuś de traicionar a Calcedonia. Revocó entonces la condena, por lo que el Concilio de Constantinopla lo excomulgó. Volvió a ceder el papa, accediendo a la condena, y varias privincias de occidente rompieron con Roma (alguna de esas rupturas duró más de un siglo). El conflicto todavía hoy no está aclarado históricamente. Pero lo innnegable es que el papa anduvo desdiciéndose y dio así el primer ejemplo de que Roma puede apartarse de la fe, rompiendo el principio de que, de hecho, nunca se había apartado de ella. La distinción (que hoy invocaría cualquiera) entre "la fe" y sus formulaciones "metafisicas" no se sabe hacer 
entonces. Y el impacto de este hecho se reflejará en unas líneas posteriores de san Columbano al papa Bonifacio IV: "es muy penoso que la sede apostólica no guarde la fe católica" (citado en Schatz, 88).

El papa Honorio fue igualmente condenado como hereje por el Ill Constantinopla. También considero discutible la condena, pues me parece claro que Honorio sólo quiso evitar las sutilezas verbales tan del gusto del oriente3. Pero es innegable su condena no sólo por el Concilio sino por papas posteriores. Con esa condena se refuerza el ejemplo de que el papa puede incurrir en herejía, que fructificará más tarde. De momento, gracias al papa Agatón, como ya hemos dicho, Roma aún salí́ bien parada de este episodio y cuando, pocos años despues, un concilio oriental (Trullanum, sin participación de Roma) publique unas decisiones disciplinares que el emperador quiere imponer a toda la Iglesia, Roma no lo aceptará.

La querella de las Imágenes enfrentó también al obispo de Roma y a los emperadores. Estos eran todos iconoclastas y, bajo su influjo, un sínodo de Constantinopla condenó las imágenes. Roma volvió a verse unida al oriente (con san Juan Damasceno) contra Constantinopla, como en tiempos de Eutiques. El II de Nicea, el 787, conden6 la iconoclastia y devolví́ a Roma un prestigio y una posición privilegiadas, que se reflejan en unas líneas con las que el Concilio declara ilegítimo al anterior sínodo de Constantinopla: "porque ni los obispos que le rodean han intervenido, ni por medio de legados ni por medio de una carta como es ley para los concilios. Pero además, tampoco los patriarcas de oriente, de Alejandrfa, de Antioquía y de la ciudad santa [Jerusalén] han dado su aprobación" (citado en Schatz, 92, cursiva nuestra).

Finalmente, el compllcado problema de Focio. Primero se trato de una cuestión intrabizantina: el litigio entre Focio e Ignacio, dos candidatos a la sede de Constantinopla. También aquí la pelea fue oscilando conforme cambiaban los emperadores. Ambos contendientes apelaron a Roma, que primero dio la razón a Focio, hasta que un concilio, con participación de legados romanos (IV Constantinopla), lo depuso y dio la sede a Ignacio. Focio intentó en vano excomulgar al papa. Pero cuando Roma, creyéndose ahora fuerte, exige que los partidarios de Focio fimen un libelo de rehabilitación, todos (no sólo los adictos a Focio) se vuelven contra esta medida, mostrando "cuán escaso había sido el grado de aceptación interna... por parte de la Iglesia bizantina" (Schatz, 94). Repuesto otra vez Focio, se crea un malentendido ya perenne, pues Roma (por razones prácticas) lo acepta, pero como "pecador arrepentido entronizado de nuevo". Mientras que oriente lo acepta como "legítimo patriarca" desde el principio.

Parecerá un tópico el balance de que esta es la historia del desentendimiento

3. Ver lo que dijo sobre ella en La humanidad nueva (8a. ed.), p. 424. 
entre la política (con sus deslices metafisicos) y la metafísica (con sus claudicaciones políticas). Pero el tópico tiene su parte de verdad. En cualquier caso y cono primera conclusión, escribe Schatz que Roma seguía siendo "importante para domeñar los conflictos intemos de la Iglesia de Constantinopla; pero su autoridad se limitaba a sancionar los resultados de la lucha por el poder que allí se registraban" (Schatz, 95-96).

A partir de aquí, el balance de todo este primer milenio, en cuanto a las relaciones entre Roma y el oriente, es que oriense no reconoce a Roma un "primado de jurisdicción" en el sentido de gobierno de la Iglesia en tiempos normales (como el accidente). Si le reconoce un carócter de norma última de la comunión que actúa sobre todo en riempos de conflicto. Oriente, a diferencia de occidente, ha vivido de la unidad entre la Iglesia y el imperio. Sólo cuando el imperio no signifique ya nada (o se crea asî) se pensará en el papado para ocupar su puesto - y aun esto no lo hacen todos los orientales. A su vez, el papado ha tratado con el oriente, dirigiéndose mucho más al emperador que a la Iglesia oriental, lo que los orientales han sentido siempre como una ruptura de la comunión eclesial.

Lo que sí se acepta de modo bastante general en oriente es que las diferencias que cuestionan la identidad de la Iglesia y de su fe, han de ser resueltas de modo definitivo en unión con Roma (Schatz, 98).

Nada más, pero tampoco nada menos. Se trata de dos visiones diferentes fruto de dos historias diferentes y de dos mentalidades muy diversas. En mi opinión, ambas tienen una suficiente "coherencia estructural" con los datos del Nuevo Testamento (donde la unidad es muy importante, pero es siempre un resultado de la comunión y la pluralidad). La historia, que permite comprender, permite a la vez relativizar. Y toda búsqueda evangélica de unidad, a la que estamos obligados por encima de todo, no podrá hacerse por la línea de imponer la propia historia a los demás, sino por la búsqueda paciente y creyente de la comunión, y hasta por la renuncia a todo aquello que son contingencias históricas.

Desgraciadamente no fue esa la evolución que siguió. Y ello va a derivar, en el milenio siguiente, en una ruptura hasta hoy definitiva4.

4. Vale la pena citar cómo expresa esa ruptura, ya en el sigo XIII, una obra de un autor occidental (Anselmo de Havelberg) escrita en forma de diálogo con el oriente: "La Iglesia romana, a la que nosolros no negamos su primacía entre las iglesias hermanas, y a la que reconocemos el puesto de honor y de presidencia en un concilio ecuménico, con su arrogancia al asumir la monarquía, que no era propia de su ministerio, se ha separado de nosotros y ha dividido a los obispos y a las iglesias de oriente y occidente, de acuerdo con la división del imperio... Aunque no discrepamos de la Iglesia romana en la fe, ¿cómo podemos, dado que actualmente ya no celebramos concilios con ella, aceptar sus decretos, que ellos elaboran sin nuestro consejo y basta sin nuestro conocimiento? Si el papa, sentado en el trono de su 


\section{La primera milad del segundo milenio}

En todo el segundo milenio, el papado irá exhibiendo la pretensión de ser, no sólo centro de unidad y norma última, sino cabeza de la Iglesia. Por extraño que parezca, esta pretensión va a salir reforzada de sus mismos fracasos (el cisma de occidente y la ruptura de Lutero). Y si se constituye en la primera milad del milenio, se convierte en señal de identidad durante la segunda mitad, en la llamada contrarreforma.

Esta evolución implica una transformación de los concilios ecuménicos: Si antes habían sido reuniones de obispos presididos por el emperador, ahora irán pasando a ser reuniones de la Iglesia universal (jno solo de obispos! que en muchos casos no pasaban de un tercio de los presentes) bajo la dirección del papa.

Esta evolución acaece no por mera voluntad romana de poder, sino "por el hecho de que el papado se mostró más capacitado para afrontar los desafíos históricos y para reconocer el alcance de aquellas transformaciones" (Schatz, 120). Este es el resumen. Veámoslo por pasos.

\subsection{Factores de esta evolución}

En primer lugar, la necesidad de libertad y reforma de la Iglesia. Tras el pecado del poder político (de papas y obispos), la comupción y la dependencia que el poder conlleva (siglo de hierro, etc.) convencen a Gregorio VII de la necesidad de una autoridad papal fuerte para garantizar a la Iglesia la reforma y la libertad. Es significativo que la Iglesia de oriente, que, a pesar del cesaropapismo, no cayó en el pecado del poder político, siente esa forma de autoridad como contraria al Evangelio, y se separa. Mientras que en occidente, las apelaciones y los procesos en Roma se convierten en verdadera avalancha: "se esperaba de la curia romana más objetividad y justicia que de las instancias locales, implicadas en

gloria, quiert lanzar improperios contra nosotros o disparamos, por así decirlo, sus decretos, y juzga de nosotros y de nuestras iglesias no por nuestro parecer, sino por su beneplácito y propio arbitrio y hasta impera sobre ellas, ¿qué clase de fraternidad o de paternidad es ésla? ¿Quién puede soportar algo así con ecuanimidad? Ya no podemos, pues, ser llamados hijos de la Iglesia, por que ya no lo serfamos, sino que seríamos verdaderos esclavos. ¿Debe ser él (el papa) el único obispo, el único maestro, el único preceptor? ¿Debe él dar cuenta únicamente ante Dios como único buen pastor, de todo cuanlo le ha sido confiado? (Citado en Schatz, 164-65). Es dificil no dejarse impresionar por el vuelo evangélico de palabras como éstas. Y será bueno compararla con la cita de Belarmino que abría este artículo. Véase también el balance del historiador oriental Geanakoplos: un “'sub Petro' que no anule el 'cum Pedro'. O, 'hermana mayor' con todos sus derechos de mayor, pero no 'Iglesia madre'" (citas en Tillard, 546-547). 
los intereses del poder local" (Schatz, 122). Y con Inocencio III, las canonizaciones pasarán a ser privilegio exclusivo del papa.

En segundo lugar, las nuevas condiciones sociales de urbanismo y mayor movilidad. A esas nuevas condiciones quieren responder también las nuevas ordenes mendicantes, cuyo obispo es el papa. Pero con esta concepción: contribuirán a la mentalidad de "un poder papal de jurisdicción inmediata que puede alcanzar a todo fiel" (Schatz, 125), lo cual explica la oposición a esas órdenes de los teólogos de la Sorbona (Guillermo de St. Amour, etc.), mientras que los teólogos de las nuevas órdenes son papalistas. Y luego irá pasando al mismo papado la concepción centralista universalista de estas órdenes. Con lo cual (escribfa Ratzinger en 1957) "le sucede al papado algo que... en modo alguno deriva de su esencia: se entiende ahora $-y$ sólo ahora- en el sentido del centralismo estatal moderno" (Schatz ,126, cursiva nuestra).

Pocos dalos como éste hacen ver hasta qué punto la vida de la lglesia está regida por la dificultad de la historia (en este caso, la siempre difícil síntesis entre universalismo y localismo), y no por una voluntad previa e inmediata de Dios. Porque si esta evolución es comprensible, no deja de tener sus peligros muy serios, que Schazz apunta también: la hierocracia (Gregorio VII se atribuye el poder de deponer a los reyes); la pérdida de contacto con la realidad (según Schatz, a partir sobre todo de Inocencio IV, hacia 1243); y el choque con las monarquías que van naciendo ahora como institución laical autónoma.

\subsection{Las elapas de esa evolución}

Las etapas pueden reducirse a cuatro.

En primer lugar, el célebre Dicıatus papae de Gregorio VII, que nuestro autor resume así: "el papa por sí solo puede hacerlo todo en la Iglesia y sin él nada de cuanto ocurra puede ser válido o correcto. El poder papal no parece conocer límites" (Schatz, 129). Según Kehl, debajo de este documento está la eclesiología del cardenal Humberto (De sancta romana ecclesia). publicada un año antes de su visita a Constantinopla, en la que excomulgó a los orientales y de la que nació la separación de la ortodoxia (Kehl, 320).

Con Gregorio VII se produce - por razones de reforma - la primera reclamación del poder para destituir, trasladar y nombrar obispos, que sólo más tarde será puesta en práctica. Se produce también una "santificación ontológica" del papa por la cual "no puede ser juzgado por nadie". Aquella época no conoce lo que nosotros llamamos "foro intemo": y si el papa peca habría de ser sometido a la penitencia eclesial, con lo que la solución para no mermar su poder será atribuirle una cierta impecabilidad. Y esta mística llega hasta extremos como imponer la liturgia romana frente a otras locales muy vivas hasta ahora, como la de Toledo. 
En segundo lugar san Bemardo reaviva la distinción antigua entre la plenirudo postestatis (que corresponde a sólo el papa) y la pars sollicinudinis (que es la que afecta a cada obispo): plenitud de poder y participación en la responsabilidad. Pese a esta teología, san Bernardo será muy crítico con la centralización de hecho, y con el boato papal que acaba implicando. Ya es conocida su doble critica en el escrito dirigido a Eugenio III: el papa parece más sucesor de Constantino que de Pedro y está convirtiendo a la Iglesia en el "monstruo de una cabeza con dedos" (es decir, sin cuerpo). Pese a ello y de manera unilateral, la eclesiología de san Bernardo influira mucho por la primera distinción y nada por sus críticas.

En tercer lugar, con Inocencio III, el título de Vicario de Cristo pasa a ser exclusivo del papa "pese a que el Decretum Gratiani le llamaba expresamente vicario de Pedro y no vicario de Cristo" (ed. Friedberg, I, 244 y 431). Antes se llamaba así a otros muchos: a los pobres, al cura, al superior, al igual o al inferior... Era un calificación más bien de "la alteridad", que ahora pasa a ser exclusiva del poder. Ello acaba llevando a una concepción del papa como alguien fuera de la Iglesia y contrapuesto a ella (cfr. Schatz, 138). Si es vicario de Cristo le compete el mismo calificativo que a éste: el de cabeza de la Iglesia. Y hasta se pretende que el arameo Kephas (piedra), deriva del griego Kepahle (cabeza). De ahí la concepción de que todo poder eclesial viene del papa y lo representa, dado que el papa no puede estar en todas partes. Una concepción que es claramente contraria a la del Nuevo Testamento.

M. Kehl califica ambos títulos como una "pretensión desmesurada" y añade que "sería bueno para la reintegración del ministerio de Pedro en el conjunto de la Iglesia, que el lenguaje católico renunciase finalmente a este título ambiguo" (cfr. Kehl, 323-324). También Tillard, comentando la doctrina de Tomás de Aquino sobre el papado, señala que se ha perdido aquí la perspectiva de definitividad (eph'apax) de la Iglesia primera de Jerusalén, unida en tomo a Pedro y los apóstoles, de modo que todas las iglesias locales son introducidas por el Espíritu en la gracia de aquella primera lglesia. En la edad media no es ésa la perspectiva, sino la de una Iglesia universal. Así es como se cambia el vicario de Pedro en sucesor de Pedro, para remontarse desde ahí al "vicario de Cristo" (Tillard, 492). Así se acepta también una jurisdicción que no deriva de la ordenación, cosa que el oriente nunca admitirá (Tillard 499)s.

Pese a todo eso, Inocencio III actuó con cierta discreción en occidente donde, por así decirlo, "dijo más que hizo". Lo nuevo en él es la pretensión de aplicar esta teoria también a la Iglesia griega que, en 1204 y en virtud de la "cruzada latina", se vio obligada a aceptar una engañosa sumisión a Roma.

5. Según este mismo autor, LG 21 efectúa un cambio en esta concepción que obliga a "repensar la relación entre la sede romana y las otras iglesias" (Tillard, 499). 
Posteriores intentos de unión tratarán de "conceder como regalo del papa" lo que los orientales reivindicaban como "derecho propio concedido por Cristo". Es claro que una unión apoyada en este malentendido no puede ser muy segura.

Por último, a partir de Inocencio IV (1243-54) puede hablarse ya de la monarquía papal absoluta. El papa se convierte, más que en vicario, en sustituto de Cristo, apoyándose en una cristología que descionoce el rostro concreto de Jesús, y para la que Cristo sólo es un esquema formal de divinidad (lo que explica las reacciones en la espiritualidad, que buscará más la "mística de Jesús", hasta llegar a la separación entre espiritualidad y dogmática). Pero esta última teorización no es obra de un papa como Inocencio III, sino de teólogos cortesanos como Egidio Romano (autor de aquella máxima tan herética como conocida: "se puede decir que la Iglesia es el papa") y Agustín Triunfo. Si hasta ahora el papa, aun con sus plenos poderes, estaba sometido al derecho eclesial, ahora se le presenta como solutus a legibus, por encima del derecho, lo que merece a Schatz el siguiente comentario:

El papa, que en principio debería estar más ligado que otros a la Iglesia y a su orden establecido, resulta estar por encima de la Iglesia, no dentro de ella. Esta comprensión del oficio papal, sumamente peligrosa por su arbitrariedad, llega hasta la "Nota previa" de la constitución sobre la Iglesia en el Vaticano II, donde se afirma que el papa, sin el Colegio, puede hacer uso de su autoridad suprema ad placitum (Schatz, 139).

En esta evolución sólo perdura una excepción importante: el peso de la historia y la tradición pasada (recogidas por ejemplo en el Decretum Grationi) siguen imponiendo la posibilidad del papa hereje, con lo que se matiza el principio de que "no es juzgado por nadie... a menos que aparezca desviado de la fe". Tal excepción queda como mera teoría, no sólo porque está en cierta contradicción con lo antes dicho sobre la santidad ontologica, sino porque nunca se acaba de decir quién lo sorprende desviado: lo que implicaría alguna superioridad del concilio sobre el papa, si no se quiere dejar al juicio de cada particular (como hizo Mons. Lefebvre).

\section{Las consecuencias de eata evolución}

La primera es la pérdida de las estructuras sinodales y episcopales, "victimas, por un lado, de un papado absolutista y, por otro, del sistema de las iglesias nacionales del incipiente Estado modemo" (Schatz 141). Buena parte de esta consecuencia se debe a la incapacidad de esas instancias inferiores para dotarse de estructuras de libertad y colegialidad. Con ello, los sínodos de la Iglesia romana se convierten en concilios ecuménicos (así los tres primeros de Letrán, según la enumeración que hace Belarmino). A través de este rodeo, se reanima la institución del concilio ecuménico, pero "estos concilios no gozan, 
respecto de la autoridad papal, de la independencia que caracierizaba a los del primer milenio" (Schatz, 142).

La segunda es el paso del nombramiento de obispos a los papas. Factores decisivos en la puesta en acto de este paso fueron, en primer lugar, las continuas apelaciones a Roma (las elecciones buscaban una unanimidad imposible, y hasta 1274, en el concilio de Lyon, no se estableció la norma de dos tercios). Y en segundo lugar, el influjo cada vez mayor de los monarcas, a los que no saben resistir los metropolitas. Por explicable que sea este paso, "parece contradecir radicalmente la intención misma de la reforma gregoriana, que precisamente se inició restableciendo por norma la libertad en la elección canónica de los obispos, que había sido remplazada por el nombramiento regio... La vinculación del obispo con su Iglesia se concibe como un matrimonio espiritual; el consentimiento de la Iglesia hacia su obispo debe ser libre, como el consentimiento mutuo de los esposos. La imposición de un obispo por el rey equivale a una violación espiritual, a un rapto de la esposa; la simonía significa convertir a la esposa de Cristo en una prostituta" (Schatz, 143).

A pesar de este juicio, hoy casi común en teología, Egidio Romano pretende justificar este paso con el paralelismo de que Dios es libre para hacer milagros, sin respetar la actuación de las causas segundas. Lo que merece de nuevo el siguiente comentario de Schatz, que deja en manos del lector la supresión de la condicional: "Se podría sacar la consecuencia de que una Iglesia en la que por principio y de modo general, los obispos fueran nombrados por Roma seria tan aberrante como un mundo en el que todo aconteciera, no por causas naturales, sino a golpe de milagro" (Schatz, 145).

Y esa aberración tiene como consecuencia la extensión de la simonía en los nombramientos episcopales por las "annatas" o rentas del primer año, reservadas a los papas. Por más que se teorice que el sacramento da a los obispos sólo el poder de orden, y el papa les confiere la jurisdicción, por más que se respeten a veces otras prácticas (siempre como concesión papal y no como derecho propio de las iglesias), este cambio merece uno de los juicios más duros de nuestro autor: "La libre elección canónica, objeto de enconado debate en la epoca gregoriana, en el que se emplearon serios argumentos espirituales y teologicos, fue abolida sin pena ni gloria por el mismo papado, y no por razones pasiorales sino puramente financieras" (Schatz, 146). En el mismo sentido, Tillard insinúa que esta forma de nombramiento convierte - velis nolis- a los obispos en lo que Vaticano II dice que no deben ser: "los obispos no deben ser tenidos como vicarios del romano pontífice" (LG 27; cfr. Tillard, 505).

La tercera y más grave consecuencia es la mayor crisis del papado, que tiene lugar con el llamado "cisma de occidente".

Teologicamente, lo más importante de este cisma está en que es una consecuencia de la teología papal anterior. Hasta aquel momento, cismas había habido 
varios, que siempre se resolvieron con la victoria de un papa o la renuncia del olro. Ahora, la teología de que el papa no puede ser juzgado por nadie, hace que la buena voluntad de aquellos hombres que sinceramente se creían papas legítimos, les impida ceder. Como explicaba Bonifacio IX, uno de los afectados, "sólo cabe confjar en la providencia divina porque toda intervención humana un concilio por ejemplo- constituía 'una presuntuosa injerencia en el orden establecido por Dios'... En el fondo era aquella absolutización del papado la que había metido a la Iglesia en el callejón sin salida del cisma" (Schatz, 149 y 198). Estos peligros habían sido señalados ya en el infructuoso concilio de Vienne (unos 70 años antes). Pero no se hizo caso. Por eso, lo más llamativo, hoy en día, es la nula atención que la teología del papado sigue prestando a este luctuosísimo acontecimiento.

Por otro lado, el cisma tiene lugar en un momento en que van apareciendo en la sociedad, aunque de manera fugaz, nuevos modelos de "autogestión corporativa" (parlamentos, cjudades, universidades, órdenes religiosas). Y ya hemos dicho lo marcada que está la evolución del papado por la evolución de la sociedad. Esto hace más comprensible la fuerza del conciliarismo en aquellos momentos, y más incomprensible la resistencia de los papas. El principio prima sedes a nemine judicafur se relee ahora como aplicado sólo al juicio de los particulares, no al de la totalidad de la Iglesia, representada por el concilio. Pero cuando, desde esta teología, el concilio de Pisa depone como herejes (por negar la unidad de la Iglesia) a los dos papas existentes, éstos se niegan a aceptar su deposición, llegándose a una situación de tres papas.

Hubo que llegar a esta situación rocambolesca y escandalosa para que por fin el concilio de Constanza pudiera resolverla, echando mano más del pragmatismo negociador que de la aplicación de teologías sin salidas. El concilio redacta su decreto Haec Sancta que servirá para deponer a Juan XXIII y a Benedicto XIII, y que tiene el valor de haber recibido una confirmación papal. El decreto afirma sobre todo dos cosas: que el poder del concilio proviene directamente de Cristo y no del papa y que, en cosas que afectan "a la fe, a la eliminación del cisma y a la reforma de la Iglesia", todos están obligados a obedecerle, incluso el papa.

Curiosamente, el papa romano Gregorio XII (dimitiendo) y su sucesor Martín V (salido del Concilio) fueron los únicos que aceptaron este decreto. Pero para ello, el concilio tuvo que transigir con una ficción jurídica: permitir que Gregorio XII, antes de dimitir, "convocara" él al concilio, con lo que, según algunos, sólo tendría valor a partir de aquel momento, olvidando la posterior aprobación global de Martín V. En cambio, el papa Luna (según Schatz "el más íntegro de los tres") se retiró a su castillo de Peñíscola, desde donde excomulgó a toda la cristiandad, aferrándose a un argumento "lefebvriano", jurídicamente irrebatible, pero que viene a ser una refutación ad absurdum de toda la teología 
anterior: si los papas del cisma han sido inválidos, también lo son los cardenales nombrados por ellos. Ahora bien, en aquellos momentos, el único cardenal anterior al cisma y todavía vivo era él. Por tanto, sólo él tenía derecho a elegir papa, no el concilio. Si el concilio no tuvo razón, la sucesión romana habría quedado interrumpida con el papa Luna, cuya resistencia estaría justificada. Si la tuvo, quizás la validez del papa romano proviene de haber sabido obedecer al concilio.

Dejemos ahora la deriva de los concilios posteriores (Basilea, Ferrara, Florencia) que intentaron dar una vuelta de tuerca al conciliarismo, proponiéndole al papa obligaciones imposibles, como era convocar un concilio ecuménico cada cinco años, con lo que se prentendió convertir en ecuménicos y representativos de la Iglesia universal lo que no eran más que asambleas de "hombres a los que sus 'beneficios' les permitían largos años de ausencia de su lugar de residencia" (Schalz, 159).

En su momento, Constanza tuvo un enorme efecto negativo, que fue el triunfo del "sistema regalista de las iglesias nacionales", que hizo que los estados pasaran una elevada factura a futuros papas. Junto con los siguientes concilios, dejó además una serie de problemas jurídicos insolubles, ya que los papas andaban convocando y desconvocando, aprobando en general o en particular, según su posición de fuerza o de debilidad ante el concilio o ante los reyes...

Hoy que esos peligros está orillados, queda a la teología la tarea de compatibilizar Constanza y el Vaticano I, en lugar de oponerlos, haciendo que se contradigan formalmente. Schatz insinúa que el Vaticano I se refiere a situaciones normales y Constanza a siluaciones "excepcionales" que el Vaticano I no considero (Schatz, 161), pero que la historia demuestra que pueden presentarse:

Cualquier eclesiología que únicamente vincule a la Iglesia con el papa, pero no a éste con aquélla, es refutada por la experiencia histórica del cisma y los sucesos concomitantes. El ejemplo de Constanza muestra precisamente que no sólo es válida la conocida formula de Ambrosio (ubi Petrus ibi Ecclesia), sino también su contraria (ubi Ecclesia ibi Perrus). No siempre es Pedro la norma inequivoca de una realidad como la de la Iglesia, que es en sí bastante más ambigua y compleja. También puede ser lo contrario (Schatz, 162-163).

Porque parece innegable que el hecho de que los papas posteriores no hicieran caso de la Iglesia, una vez superado el cisma, en la otra cuestión pendiente que era la reforma, constituye una de las causas más decisivas y una de las razones más válidas, que explican la posterior ruptura de Lutero, un siglo después.

Y es así como llegamos a las Iglesias rotas, como fruto, no sólo de los pecados humanos que andan siempre por todas partes, sino de la discutible evolución del papado desde finales del primer milenio. De ahi que -rotas las iglesias- el tema del papa se va a convertir extrañamente en materia, no de 
configuración de la Iglesia ni de voluntad de Jesucristo sobre ella, sino de "identidad confesional". Así ocurre en la segunda mitad del milenio.

\section{La segunde mitad del milenlo}

\subsection{Le Contrarreforma}

Pese a que el papado era el punto decisivo de disensión con la reforma, como han mostrado los tiempos posteriores, Trento no consiguió definir nada sobre el papa, debido a la división de opiniones entre los padres. Ni siquiera logró imponer la "definición" del florentino y estuvo a punto de irse a pique por esta cuestión.

Esta paradoja tiene una razón bien comprensible: la necesidad de reforma. Schatz pone el ejemplo de la obligacion de residencia de los obispos, que era un desastre en la Iglesia pretridentina. Tal obligación resultaba coherente desde una eclesiología no sólo papista, para la que el lugar está unido a la esencia del ministerio episcopal; por lo que ni el papa puede dispensar de ella. Pero era mucho menos clara desde una teología "papista", para la que el episcopado es "un cuerpo móvil de funcionarios" (Schatz, 180).

No hubo, pues, acuerdo eclesiológico en Trento (ni siquiera hoy se ha logrado bien la síntesis). Y los padres más papistas transigieron en no definir nada, por la necesidad de reforma en el tema de la residencia (algo similar a lo que antes había tenido que hacer Constanza, pero al revés). Por eso, según Schatz: "lo sorprendente es que, unos trescientos años más tarde, un concilio de obispos (Vaticano 1) definiera las prerrogativas del papa de una manera que habria resultado impensable en Trento" (Schatz, 180, cursiva nuestra). Hay que analizar las causas de este hecho sorprendente.

Está en primer lugar lo que Schatz ha llamado "identidad confesional". Los católicos pasarán a ser llamados "papistas" y se defenderán, como Belarmino, mostrando las ventajas de esa constitución para la unidad de la Iglesia. La eclesiología se convierte en apologética (Schatz, 185).

En segundo lugar, ello está favorecido por el innegable liderazgo de algunos papas en la reforma de la Iglesia: algo semejante al caso de Gregorio VIl y que vuelve a favorecer el centralismo. Aparecen así las nunciaturas, se funda la inquisición "romana", se crea la congregación de propaganda fide y hasta la liturgia se uniformiza con el misal de Pío V6.

6. Es sabido que ese misal de Pío $V$ fue una de las razones del cisma de Lefebvre tras el Vaticano II. Esta postura que parece tan absurda, resulta más lógica si leemos la bula Quo primum de Pío V, en 1570 , en la que amenaza con excomunión a quien añada, 
En tercer lugar, la razón mayor parece ser la falta de altura histórica de las fuerzas "centrífugas", que acabarán absorbidas por la revolución francesa. Este proceso puede resumirse más o menos así.

Al ser el papa un monarca, acabará actuando más a través de los otros reyes, que de los obispos7. Ello dará poco a poco a los soberanos una gran fuerza ante el monarca de Roma. Y para canalizar esa fuerza en beneficio propio, buscarán apoyarse en los obispados: de ahí el auge de iglesias nacionalistas, galicanismos y febronianismos, etc.8. Las iglesias locales, metropolitanas, patriarcales, se convierten ahora en iglesias nacionales. Con ello, las fuerzas eclesiales compensadoras del papado pierden su rostro tradicional y se convierten en fuerzas pollticas. Y en el inconsciente de un papa monarca habrá siempre más miedo a unos rivales políticos que a un contrapeso eclesial.

Se trata de un problema todavía no bien resuelto en la Iglesia: una ambigüedad semejante a la que, en la primera mitad del segundo milenio, se había planteado entre occidente y oriente: la ambigüedad entre hierocracia y cesaropapismo, es decir, una libertad de la Iglesia que no se confunda con el poder político monárquico-papal, y un respeto a los otros miembros del cuerpo eclesial que no se confunda ahora con una especie de "cesaroepiscopalismo"

quite o cambie algo del misal, concluyendo: "Sepa quien se tome esa libertad, que incurre en la ira de Dios todopoderoso y de los santos apóstoles Pedro y Pablo". Eso es lo que para los seguidores de Lefebvre hablan hecho Juan XXIII y Pablo VI. Cfr. H. Waldenfels, "Unfeblbar. Uberlegungen zur Verbindlichkeil christlicher Lehre", Stimmen der Zeit, marzo, 1966, 147-159.

7. Algo semejante a la acusación que se hace a Lutero de haber impuesto la reforma gracias a los principes. Un católico no deberín usar mucho esa argumentacion, si lee las siguientes palabras de Schatz: "los príncipes resultaban extremadamente importanles de cara a la conirarreforma y a su puesta en práctica, y a menudo las medidas reformistas de Trenlo se imponían de modo más eficaz gracias a la acción decidida de los soberanos que a la buena voluntad de los obispos" (Schatz, 186).

8. Expresiva me parece esta cita del Congreso de Ems (1786), en el que lomaron parte varios obispos alemanes: “El papa romano es y será siempre el supremo supervisor y primado de la Iglesia universal, el centro de la unidad, a quien Dios ha dotado de la jurisdicción necesaria a este respecto, y todos los católicos deben prestarle la obediencia canónica con obsequioso respeto. Pero todos aquellos privilegios y reservas que en los primeros siglos no están asociados a este primado, sino que emanan de las Decretales Pseudoisidorianas posteriores, en detrimento manifiesto de los obispos, no pueden ser incluidas bajo aquella jurisdicción, ahora que la suplantación y la falsedad de las mismas han sido suficientemente probadas. Esas prerogativas forman parte de las injerencias de la curia romana, y los obispos están autorizados para ejercer sus funciones propias según el poder que Dios les ha concedido y bajo la suprema prorección de su majestad imperial (Schatz, 194. De no ser por la última frase que he subrayado, este párrafo tendría hoy absoluta vigencia). 
(aunque Schatz no quiere hablar de "servilismo" de los obispos respecto a los reyes, sino más bien de una "dinámica interna", que hacía que esos movimientos "estuvieran abocados a ser engullidos por la marea del sistema regalista" (Schatz , 196).

Pero Schatz no cita aquí otro factor del que hablará más tarde y que me parece ser el reverso del anterior (de modo que no todo estaría en la falta de altura histórica de las corrientes comunitarias frente a la personalista). Me refiero a la aparición del llamado ultramontanismo, en el siglo XIX: un movimiento de carácter político, producto del pánico creado por la revolución francesa, que busco en el falso recurso a la religión una seguridad frente a los temores de la revolución. Fábrega dedica buena parte de su libro al análisis de este movimiento, que además se lleva un capítulo expreso (pp. 68-97), y que liene la gran virtud de no limitarse a los representantes politicos del movimiento (Bonnald, De Maistre, etc.), sino que añade citas de teólogos y obispos (de esos que nunca "hacen política"), que participaban de las ideas ultramontanas y ayudaron a dar camuflaje teológico a un interés político. Señalo tres puntos para caracterizar este movimiento.

Lo que Schatz califica como "paso de la testificación a la determinación de la verdad" (Schatz, 204), basado en el principio atemorizado de que sólo la autoridad puede salvamos. Es lo que propugnaba el dicho otras veces citado de Bonnald: "es hora de pasar de la auloridad de la verdad a la verdad de la autoridad", el cual queda maravillosamente comentado en una carta de De Maistre sobre la infalibilidad, dirigida a un monseñor romano: "si los dogmas [de la religión] son fábulas, es preciso, por lo menos, que haya unidad de fábulas, cosa que no existirá jamás sin unidad de doctrina y de autoridad, la cual, a su vez, no es posible sin la supremacía del Sumo Pontífice" (Fábrega, 78). Herético sí, pero "más claro agua". Lo de menos es la verdad, lo decisivo es el orden, sea cual sea?.

Consecuencia de lo anterior: el papa no es lestigo, sino "fuente" de la verdad y "el 'sentir con la Iglesia' pasa a ser 'sentir con el papa"" (Schatz, 209). Un movimiento que, muy hábilmente llevado por el populismo simpático y

9. Hasta qué punto estos principios téricamente condenados influyen en la práctica de la Roma actual lo pone de manifiesto el procedimiento sutil por el que hoy se intenta presentar como "testificación" lo que no es más que una "determinación". Ante cuestiones debatidas que están en la mente de lodos no puede haber una testificación (ipues las testificaciones serian diversas!). Se recurre entonces a nombrar obispos sólo a quienes compartan una determinada postura y a prohibir a los nombrados que hablen en contra de la posiura que se pretende imponer. Así se espera que, al cabo de un tiempo, lo que era una determinación secreta, se haya convertido en una testificacjón aparente. 
victimista de Pío DX, se convierte en un fenómeno de masas: de hecho, en el siglo XIX vuelven a aparecer las peregrinaciones a Roma, pero ahora ya no se va para ver las tumbas de los apóstoles mártires, sino para ver al papa (Schatz, 210). Y que recibe expresión teológica en el comentario del teólogo C. Schrader nada menos que al lamentable Syllabus de Pío IX: "por boca de Pío ha hablado Pedro, lo que él ratifica o rechaza queda establecido en virtud de su juicio infalible e irreformable y, como tal, así permanece" (ver Fábrega, 86). Estemos a 180 grados del significado que dio Calcedonia al Petrus per Leonem locurus est.

Hay una tercera característica en la que Schatz y Fábrega parecen disentir. Sin embargo, me parece que ambos exponen posturas reales de los ultramontanos, que en este punto no coincidian. En algunos de más buena voluntad religiosa, la importancia de Roma reside en que es puntal de libertad de la Iglesia frente a los estados (un problema que ha venido amastrándose durante toda la historia anterior): así sentía la buena voluntad ultramontana del primer Lamennais (cfr. Schatz, 205). En cambio, para De Maistre, cuyos intereses son mucho más políticos, "la Iglesia es una elipse que tiene dos focos, Roma y París; en el uno está san Pedro, en el otro Carlomagno" (citado en Fábrega, 71). Un factor fundamental en el entusiasmo de muchos laicos y clero joven de la época.

Estos tres factores hacen muy compresible la llegada desde la postura respetuosa de Trento hasta la unilateral del Vaticano I. Pero antes de entrar en éste, conviene exponer además las consecuencias de este proceso.

Todas giran en tomo a una debilitación de la teología de los dominicos de Salamanca (Vitoria, Cano, etc.). Estos teólogos enseñaban que el concilio ecuménico tiene autoridad inmediata de Dios y no mediante el papa; y señalaban la necesidad de que el papa se sirva de los medios humanos y cuente con el apoyo de la Iglesia antes de actuar. Poco a poco (sobre todo con Belarmino) este dato se convertirá de "necesidad eclesiológica" en "obligación moral". Y se va dando por sentado, desde lo que suelo llamar "monifisismo pneumatológico", que "Dios garantiza que de hecho el papa siempre lo hace asî" (Schatz, 184), cuando es la historia quien debe mostrar si de hecho ha sido asf. Aqui tenemos la segunda tentación de Jesús ante Satanás.

Así, llegamos por fin al Vaticano l, sobre el que Fábrega y Schatz se encuentran más separados que en lo relativo a la historia previa. Por lo que habremos de atender sobre todo a las diferencias entre ambos.

\subsection{Vaticano I}

Quiero comenzar señalando un punto de coincidencia. Ambos autores subrayan muy expresamente que el papalismo de Vaticano I no es debido tanto al ansia de poder romana, cuanto a presiones del pueblo de Dios, en aquella hora 
histórica de desconcierto. Fábrega lo hace sobre todo con un análisis de los ultramontanos y de su influjo sobre muchos obispos del Vaticano I. Schatz aduce una cita de Alex de Tocqueville a la que califica de "muy acertada": "Era mayor la presión de los fieles sobre el papa para que ése actuara como señor absoluto de la Iglesia, que la del papa sobre los fieles para que se sometieran a su señorio. La actitud de Roma era más efecto que causa" (Schatz, 207).

Difieren al menos en dos puntos. Primero en la aceplación o rechazo de las tesis de Hassler sobre la neurosis de Pío IX y la falta de libertad del Vaticano I, que según Hassler harían a este concilio inválido. Fábrega simpatiza con estas tesis y acusa a Schatz de que, aunque las niega apelando a la recepción posterior, acaba dándoles la razón a base de concesiones concretas (cfr. Fábrega, 120).

No voy a entrar en este punto, que no es simplemente para lectores de historia, sino para especialistas. Puede ser que el modo verbal de Hassler le haya quitado credibilidad. Se puede remitir al lector a la historia del Vaticano I, publicada por Mons. Aubert, que ya es bastante impresionante10.

Tampoco me siento capacitado para entrar en el otro punto que separa a Fábrega y Schatz: si esas innegables dobles medidas y faltas de libertad llegan a invalidar el concilio o si - como sostiene Schatz- tampoco son mayores que las que hubo en otros concilios (por ejemplo, por causa del emperador)11. Estoy dispuesto a aceptar que la pura libertad no se da nunca porque sus mediaciones la empañan siempre. Pero quisiera añadir que la comparación con la intervención de los emperadores antiguos no me acaba de satisfacer. Aquélla fue una limitación impuesta más por la densidad de la hora historica que por la falta de caridad evangélica como fue el caso en el Vaticano $I$. Y es extraño esperar que actúe el Espíritu donde falta el primero de sus frutos, que es la caridad.

Nuestros autores difieren también en que a Fábrega parece obsesionarle so-

10. En la Historia de los concilios ecoménicos, vol 12, Vitoria, 1970. Un solo detalle que no resisto a citar: la respuesta de Mons. Manning cuando le pedian un texto más integrador respecto a las posiciones de la minoría: "los herejes vienen al concilio para ser escuchados y condenados, no para tomar parte en la formulación de la doctrina" (op. cis, 135), palabras que Pfo IX comparta y que contrastan como la noche y el día con la actitud de Pablo VI, en el Vaticano II.

11. Schatz, a pesar de todo, reconoce que "Pío $\mathbf{X X}$ se mostró muy poco sensible a las razones de la minoria, basadas en el rigor pastoral y en importantes consideraciones teológicas. A su juicio, la oposición de los obispos de la minoría estaba animada por concesiones 'mundanas' al espiritu del tiempo, a la opinión pública o al deseo de los príncipes" (Schatz, 214). Duro párrafo que, comparado con la primera parte del libro de los Hechos, casi define lo que no debería ser el ministerio petrino en la Jglesia. 
bre todo el que el Vaticano I erró al declarar como históricas cosas que no lo son (en la misma línea de las tesis de Salaverri antes citadas). He subrayado el "sobre todo", porque, de hecho, tampoco Schatz niega este enror histórico. En un artículo poslerior en la revista Catholica, al que enseguida aludiré, y donde se pone de manifiesto que la justificación del papado es teológica y no bíblica ni histórica (con lo que volvemos al Belarmino que abría este boletín), Schatz llega a escribir que un primado listo ya desde el principio, según la concepción del Vaticano I, es para el historiador eine unvorstellbare Erscheinung (una representación inimaginable).

Sin embargo, es ley hermenéutica aceptada que el magisterio de la lglesia no se extiende ni a los conceptos filosóficos que asume en una definición (hyposthasis, physis, forma corporis...) ni a los hechos históricos que pertenecen a una ciencia profana. El decreto tridentino sobre el pecado original creía que la interpretación que propone de Romanos 5,12 , era la que había dado siempre la Iglesia. El conocimiento de la historia desmiente ese "siempre" y lo empequeñece llamativamente (lo cual, por supuesto, no dejará de tener sus repercusiones a la hora de una hermenéutica del pecado original). Más clamoroso es el otro ejemplo ya citado: lo que en Trento es una divina ordinatione (y en un canon) se ha convertido en el Vaticano II en un modesto $a b$ antiquo. Un cambio que casi puede resumir toda la controversia actual sobre el ministerio petrino y que, naturalmente, tampoco dejará de tener consecuencias a la hora de hacer una hermenéutica de éste.

Una vez hecha la comparación, quisiera decir que la exposición de Schatz se centra demasiado, a mi modo de ver, en el tema de la infalibilidad, gue no es exactamente el del primado, aunque esté muy unido con él, y aunque fuese el más sonoro de aquel concilio. Prescindiré de este punto en mi exposición y me limitaré a señalar una importante clave hermenéutica de carácter cultural.

Lo que estuvo en juego en el Vaticano I no fue tanto el problema del ministerio petrino, sino la opción de la Iglesia enire una modernidad naciente, a la que habla que evangelizar, inculturándose en ella, y una obstinación en lo antiguo, que utilizaba el miedo histórico de aquella hora, para compensarlo con un refuerzo de la autoridad12.

Permítaseme comentar que se trata de un proceso semejante al del Leviathan de Hobbes. En el fondo estuvo una cuestión de eficacia pragmática: el autoritarismo es más rápido que la democracia. Y la situación del mundo era vista como una situa-

12. Scliatz, 213: “¿Debía la lglesia presentarse preferentemente bajo el estandarte de la autoridad sólida e inalterable, o más bien como una realidad histórica, expuesta ella misma al cambio, y que aceptaba el desarrollo de la jibertad moderna como una realidad conforme al evangelio?". 
ción de urgencia: "para la mayoría lo primero y fundamental era la claridad, la solidez, la seguridad y el evitar todo tipo de ruptura interna" (Schatz, 220).

Esto lleva a la pregunta de si la Iglesia del Vaticano I no ha caído en el pecado de absolutismo. Y hay que recordar que, en el congreso de la revista Concilium, en Lovaina, en 1990, J. Moltmann habló de que "en toda Europa no queda más que un estado totalitario", refiriéndose al Vaticano. Schatz viene a responder que en teoría no es así, si por absolutismo se entiende "que, junto al poder central monárquico y sometido a él, no existe ningún otro poder de derecho propio"; y se apoya para esto en otros textos del Vaticano I. Pero en cambio, concede que es así en la prácrica: "la postura fáctica posterior al Vaticano I adoptada por el papa frente a los obispos responde ampliamente al concepto jurídico de 'absolutismo'" (Schatz, 222).

En cualquier caso, he aquí el juicio global del autor catalán sobre el alemán: "el limitarse a constatar la lenta gestación de un primado romano en la historia con la indebida apropiación de unos privilegios petrinos, en sí mismos intransferibles, para justificar su lucha por el mantenimiento de una unidad eclesial medida con sus criterios, no aporta nada en favor de la legitimación teológica de los mismos" (Fábrega, 127): Volveré sobre este juicio crítico que, en mi opinion, Schatz casi aceptaría.

Pero la polémica entre estos dos autores resulta insuficiente porque, al centrarse en la infabilidad o en las condiciones previas al Vaticano I, no entran en el punto más decisivo: la doble lectura que puede hacerse de este concilio. La que hizo el canciller Bismark, que parece avalada por la práctica posterior de la curia romana, como insinura Schatz, y afirma expresamente J. Fischer en (AA. VV., 62), y la que, en respuesta a aquél, hicieron los obispos alemanes, en una carta avalada por Pio DX13. Kehl sí que cita este documento y señala que lo que el Vaticano I "excluye radicalmente a nivel teológico" queda abierto en una línea fáctica "y esa posibilidad no es descartada con claridad por la praxis postvaticana" (Kehl, 330-331).

Metodólogicamente, ambas lecturas del Vaticano I se reducen a si hay que interpretarlo sólo a la luz de él mismo o si hay que leerlo a la luz de toda la tradición previa, de Constanza y del Vaticano II. Tillard señala a este respecto que "LG 22 ya no habla de un poder primacial 'inmediato' y 'verdaderamente episcopal'; sino que habla de un 'poder pleno, supremo, universal' [...] sobre toda la lglesia" (Tillard, 500; cfr. Kehl, 345).

\section{Despnés de 1870}

Por lo que toca al siglo XX y al Vaticano II, último capítulo de esta larga

13. Y que sólo después del Vaticano II fue recogida en la nueva edición de DS 3112 3116. 
historia, la tesis de Schatz podría resumirse diciendo que la cuestión sigue abierta, pero sólo en teoría. Después del Vaticano I, mientras la infabilidad ha resultado poco práctica y poco practicable, el primado papal ha crecido aún más. Las encíclicas sustituyeron a las definiciones infalibles, con clara aceptación en los comienzos, hasta llegar a la crisis de la Humanae Vitae (cfr. Schatz, 228).

Por lo que toca al Vaticano II, aunque quiso equilibrar al Vaticano I, "no se atrevió a ser consecuente y a definir el primado exclusivamente como centro del colegio... Esto significa que en el fondo no se ha conseguido la conciliación. La eclesiología de la jurisdictio, es decir, la del Vaticano I, y la aún más antigua eclesiología de la communio, ahora redescubierta, han sido yuxtapuestas y continúan estando disociadas" (Schatz, 230 y 231, subrayado mío). Su colega alemán, yendo más allá de la literalidad, señala tres principios teológicos del Vaticano II, que son decisivos para su eclesiología y su visión del primado: además de la colegialidad, "la cooriginariedad" y "la praxis de integración y diferenciación" (Kehl, 341-344).

Pero la conclusión de todo este proceso, según Schatz "no es precisamente tranquilizadora" (Schatz, 232). Por una serie de razones sería fatal que la Iglesia del Espíritu no incorpore e integre las tendencias comunionistas, colegiales, episcopalistas..., limitándose a rechazarlas como "galicanas", etc. (cfr. Schatz, 236). Podría ser terrible que la Iglesia no tenga prevista "la necesidad de un correctivo intraeclesial ante la eventualidad de que el portador del ministerio de Pedro resulle indigno o no cumpla las expectativas mínimas" (Schatz, 243-244, subrayado del autor); pues si algo muestra la historia es que esa eventualidad no puede excluirse con apelaciones a la protección divina14.

Serfa malo que el primado no contase "con la realidad del consenso y la recepción" (Schatz, 241), valiéndose para ello de "la política sistemática de nombramiento de obispos en orden a favorecer determinadas tendencias intraeclesiales, sobre todo al servicio de las posiciones del magisterio, fenómeno propio de estos últimos años" (Schatz, 229).

Sería fatal que Roma entienda "su función preferentemente en el plano de la eficacia y la administración, cediendo a un intento de racionalización que destruye su verdadera autoridad" (Schatz, 241).

Sería fatal que el servicio a la autoridad se haga consistir sólo "en servir de freno antes del precipicio", porque "si hay que evitar un cisma, es mejor hacerlo

14. Quiero añadir que las alusiones bechas a Lefebvre en este articulo se deben a que su caso parece tener valor de sintoma en este punto: si ese correctivo no esté regulado, surge el peligro de que alguien "se tome la justicia por su mano" (convirtiéndose luego en grupo minoritario de presión). 
antes, cuando aún no sea imprescindible tomar medidas drásticas" (Schatz, 239), cosa que la historia ha enseñado suficientemente en los cismas pasados y que a uno le hace temblar cuando piensa en la América Latina del futuro...

$Y$ es importante notar que todo esto lo escribe alguien que declara haber hecho una opción reologica previa por la unidad y que ve en esa opción la mayor razón teológica en favor del papado15. Pero concluye su obra con estas palabras: "El encargo que recibe Pedro de confirmar a sus hermanos está sujeto a una condición: 'cuando te hayas convertido' (Lc 22, 32). El confirmar en la fe no es propio del Pedro firmemente seguro de st mismo sino del Pedro que ha pasado por el crisol de la humillación y ha sido objeto de la corrección fratema" (Schatz, 245, subrayado mío).

\section{Conclusión}

J. Ratzinger ha señalado que la lglesia católica no puede ni necesita pedir hoy a la Iglesia ortodoxa el reconocimiento del ministerio de Pedro en mayor grado de lo que lo hizo en el primer milenio. Algo parecido cabe afirmar sobre las iglesias y las comunidades eclesiales que nacieron de la reforma. No hay por qué buscar una mayor unidad ecuménica de la Iglesia en e] futuro partiendo del modelo de unidad que existe hoy dentro de la Iglesia católica (Kehl, 349).

Esta conclusión de Kehl me parece ser la que brotaría de esta larga panorámica histórico bíblica. Y no estaría tan lejos de lo que dice Fábrega en su conclusión, sacándose un oportuno as de la manga: la palabra "herejía" (que ha titulado su libro) significa en su origen parcialidad, elección. "La herejía vaticana" sería en realidad "la parcialidad vaticana". Y esa elección se apoyaría en el mismo pluralismo del Nuevo Testamento:

Cada una de las iglesias puede encontrar en este pluralismo biblico su legitimación relativa, es decir, una legitimación que hace transparente su parentesco con alguna de las concepciones eclesiológicas neotestamentarias, pero que en modo alguno le permite erigirse en algo absoluto por encima de las demás (Fábrega, 135, subrayado mío).

Mis reflexiones finales sólo pretenden apoyar esta conclusión del teólogo alemán y el catalán.

15. Asl lo declara expresamente Schatz en un número de la revista Catholika de 1996, dedicado al papado de Pedro, en el que colaboran teólogos de diversas confesiones. Su artículo se titula: Unkonventionelle Gedanken eines Kirchenhistorikers zwm pajpstichen Primat (ver sobre todo pp. 171ss). Por eso he dicho hace un momento que Schatz casi aceplarfa la critica que le hace Fábrega. La pregunta final radica en lo que se entiende por "unidad", punto éste en el que el alemán tambien hace matizaciones importantes. 
Ha de haber quedado claro que el fondo de la cuestión del papado no es un asunto bßlico normativo, sino un asunso teológico. Estamos otra vez en el modo de argumentar de Belarmino, que abría este artículo. La pluralidad, tanto de los testimonios bíblicos como de los datos históricos, impide hacer de este tema una especie de absoluto (o de ídolo), como es sin duda la resurrección de Jesús para un cristiano. Y la famosa "jerarquía de verdades" del Vaticano II habría de comenzar a aplicarse por aqui, pues el mandato de la unidad de todos (Jn 17, 20-23) es para un cristiano mucho más vinculante que el de una determinada configuración del ministerio petrino.

Ateniéndonos a las razones teológicas, éstas no pueden girar en torno a cuál es la forma superior de gobierno (como hacía Belarmino) sino, como exponen más sensatamente Schatz y Kasper, en torno a una opción por la unidadi6. La unidad es una necesidad de la historia, y una tremenda dificultad en la historia. $Y$ este artículo ha puesto de relieve cuántas decisiones en la configuración del papado fueron debidas a esa "fuerza de la historia". Estaríamos pues ante una opción ambigua, semejante a la de la monarquía en el Antiguo Testamento. Por algo hay en la Escritura (al menos) dos versiones teológicas sobre la monarquía.

Pero una vez aceptada esa opción "católica" por la unidad queda una pregunta ulterior igualmente importante: de qué unidad se trata. Es en esta pregunta donde el Nuevo Testamento tiene algo que decir (y muy importante). La verdad cristiana, desde la encamación, es siempre dialéctica. Por eso, con frecuencia, la manera de matizar una verdad no es quitarle intensidad, sino dar toda la intensidad debida a la verdad contrapuesta. Es lo que ocurre en el princeps analogatum de divinidad y humanidad de Jesús. Pascal había dicho que muchos herejes no lo son por lo que afiman, sino por lo que no afirman. Y esio parece ocurir también en el tema del papado, sobre todo si se tiene en cuenta que el Vaticano I quedó por acabar, pero que luego se le consideró (en parte por manipulación de las fuerzas ultramontanas insatisfechas) como una verdad concluida y absoluta. Es en este sentido como cabría hablar de "herejía" vaticana, lo cual, como el mismo Fábrega reconoce, es algo muy distinto de su concepto tradicional y canónico (cfr. Fábrega, 133).

En el caso del papado hay en juego dos principios contrapuestos: el ya mencionado de respeto a esta dura historia, en la que la necesidad de la autoridad y los peligros de la disgregación forman parte de la "autonomía de lo creado" y además el afán cristológico por la recpitulación de todo y de todos, en una

16. Schatz habla de "eine theologisch begründete Option für die Einheit (art. cit. en nota anterior, p. 171; subrayado del original). Kasper habla de un primado pastoral más que jurisdiccional y lo fundamenta como "lugar de protección de la libertad, centro de unidad y comunicación" (AA.VV., 36). Formulaciones que evocan mucho más el primado de los cinco primeros siglos que el de épocas posteriores. 
koinonia que refleja al Dios amor. Permítaseme calificarlos, parodiando a Freud, como "principio de realidad" y "principio de evangelio". Ambos son, si se quiere decir así, principios teológicos: el principio de unidad autoridad y el principio de comunión consenso. Por eso, Kasper no habla simplemente de unidad, sino de "unidad de comunión entre las iglesias" (AA. VV., 53). La paradójica formulación de san Agustín y Gerson, de que el primado fue dado no a uno sino a la unidad, expresa esa misma dialéctica y marca un contraste innegable con la siluación actual 17 .

Desde esta dialéctica se puede preguntar a toda la historia que hemos expuesto hasta qué punto no hay en ella una decantación cada vez más parciah que rehuye la cat-olicidad (el afan por la totalidad) casólica. Un proceso que llega primero hasta san León Magno (s. V), donde el papado aparece como "centro de unidad", deriva después, hasta Inocencio III (s. XIII), en un papado como monarquía absoluta, $y$ va a dar en el Vaticano I (s. XIX), en una teologización unilateral del papado.

En esta teologización se sacraliza inevitablemente una noción meramente formal de la autoridad18. Se pierde así de vista lo que decíamos antes y en lo que Schatz ha insistido suficientemente: que la autoridad de Roma fue brotando de sus actuaciones integradoras (probablemente al ejemplo del Pedro histórico) y solidarias ( $f r$. Schatz, 41). Y se comprende el dato -convertido ya en tópico- de que el Vaticano II trató de recuperar la definición de la Iglesia como "comunión": pues, si juntamos como en un silogismo dos expresiones típicas de la edad media (papa potest dici Ecclesia de Gil de Roma y papa est nomen iurisdictionis de Agustín Triunfo) la conclusión es que la Iglesia es mera jurisdicción. Una conclusión, muy poco católica, y heterodoxa, en la que la comunión neotestamentaria brilla por su ausencia.

Por eso aparece como tarea para el futuro, y no sólo tarea ecuménica, sino derivada del seguimiento de Jesús para la misma Iglesia romana, la necesidad de recuperar dialécticamense el aliento utópico (o el principio Evangelio) en el tema de la auforidad del papa. La tradición creyente judeocristiana está profundamente marcada por un aliento igualitario que brota precisamente de la soberanía exclusiva de Dios. Por eso, el paso de los jueces a la monarquía es visto como una traición a Yahvé. Y si el éxito inicial de la monarquía da la vuelta a

17. Has claves non homo unus sed unitas accepir Ecclesiae (Serm. 295, 2, BAC, XXV, p. 258) Y Gerson: non uni sed unitati (Oeuvres, ed. Glorieux, III, 301, VI, 47). Permítaseme evocar otra vez a Pascal: "la unidad que no depende de la multitud es tiranía" (Pensées, 871).

18. En paralelo con lo que he dicho en otros momentos de que la escolástica hace de la divinidad de Jesús un mero principio formal de valoración de actos, carente de contenido y, por eso, de revelación de Dios. 
este argumento y convierte al rey en "ungido de Yahvé", su desintegración posterior y la división del pueblo (en un paralelismo innegable con la división de las iglesias), parece devolver la razón a los enemigos de la monarquía, o buscar la síntesis en la esperanza de aquel "descendiente de David" que nunca llega.

Es además inevitable, dada la psicología humana, que una tradición de más de mil años de monarquía absoluta temporal en el ejercicio del papado ( $y$ de una monarquía a la cual no se renunció para ser fiel al evangelio, sino que fue arrebatada por la fuerza de Garibaldi), genere un inconsciente de monarquía absoluta espiritual del que tampoco es fácil desprenderse. Por eso voy a permitime evocar, para concluir, una célebre página antimonárquica, de los orígenes de la revelación biblica.

Una vez fueron los árboles a elegirse rey y dijeron al olivo: "sé nuestro rey". Pero el olivo dijo: “ ¿y voy a dejar mi aceite con el que engordan dioses y hombres, para ir a mecerme sobre los árboles?". Entonces dijeron a la higuera: "ven a ser nuestro rey". Pero la higuera dijo: “ ¿y voy a dejar mi dulce fruto sabroso para ir a mecerme sobre los árboles?". Entonces dijeron a la vid: "ven a ser nuestro rey". Pero la vid dijo: "Y voy a dejar mi mosto que alegra a dioses y hombres para ir a mecerme sobre los árboles?". Entonces dijeron todos a la zarza: "ven a ser nuestro rey". Y les dijo la zarza: "si de veras quieren ungirme rey vuestro vengan a cobijarse bajo mi sombra, y si no salga fuego de la zarza y devore a los cedros del Libano" (Ju 9, 14-16).

En mi opinión, esta página debería leerse en voz bien alta en todas las consagraciones de nuevos papas, sustituyendo a esa desvaída fómula del sic transit gloria mundi, que quizá fue puesta con la misma intención, pero que hoy ya no es significante.

Nada que objetar, por tanto, al dato de que a lo largo de la historia haya ido constituyéndose un papado. Las objeciones surgen cuando se le constituye en el único punto de referencia eclesial, como si los afanes de comunión de todos, de inversión evangélica de la autoridad, etc., no fueran auténticas instancias evangélicas, sino fiebres quijotescas. O cuando a esa evolución histórica (que como toda la historia tiene muchos pasos discutibles) se la quiere presentar como impuesta por la Escritura y las fuentes de la revelación, ya desde el comienzo. 0 cuando, apoyándose en lo anterior, se pretende convertir la autoridad formal y personal en presencia de Dios (sacralizando el error ultramontano condenado). Y finalmente, cuando así se niega toda posibilidad al verdadero deseo de Cristo ("que todos sean uno").

Si, pues, se trata primariamente de una cuestión histórico teológica, y si el impulso evangélico reclama también aquí un complemento al principio de la dureza de la historia, y si además nuestra panorámica histórica ha puesto de 
relieve que muchas deformaciones autoritarias no acaecieron por mera voluntad romana de poder, entonces, es legítimo concluir que hoy en dla Dios parece reclamar a su Iglesia una profunda revisión del ministerio petrino. Así lo intuja también Juan Pablo II, en la encíclica citada al comienzo de este artículo. Desoír todas estas razones sería incurrir en el reproche del maestro de "quebrar el mandato del Señor acogiéndose a la tradición de nuestros mayores" (Mt 15, 3).

19. Concluido este artículo he tenido conocimiento de otras dos obras: la de J. Orlandis, a la que una recesión en Vida Nueva se atreve a calificar como "más papista que el papa", y la del Institulo A. Móhler (Das Papstamt), que ya no han podido entrar en él. No obstante son una señala de que el tema está en auge. 